\title{
Research
}

\section{Model-Based Estimation of Collision Risks of Predatory Birds with Wind Turbines}

\author{
Marcus Eichhorn $^{1}, \underline{\text { Karin Johst }}^{1}, \underline{\text { Ralf Seppelt }}^{1}$, and Martin Drechsler ${ }^{2}$
}

\begin{abstract}
The expansion of renewable energies, such as wind power, is a promising way of mitigating climate change. Because of the risk of collision with rotor blades, wind turbines have negative effects on local bird populations, particularly on raptors such as the Red Kite (Milvus milvus). Appropriate assessment tools for these effects have been lacking. To close this gap, we have developed an agent-based, spatially explicit model that simulates the foraging behavior of the Red Kite around its aerie in a landscape consisting of different land-use types. We determined the collision risk of the Red Kite with the turbine as a function of the distance between the wind turbine and the aerie and other parameters. The impact function comprises the synergistic effects of species-specific foraging behavior and landscape structure. The collision risk declines exponentially with increasing distance. The strength of this decline depends on the raptor's foraging behavior, its ability to avoid wind turbines, and the mean wind speed in the region. The collision risks, which are estimated by the simulation model, are in the range of values observed in the field. The derived impact function shows that the collision risk can be described as an aggregated function of distance between the wind turbine and the raptor's aerie. This allows an easy and rapid assessment of the ecological impacts of (existing or planned) wind turbines in relation to their spatial location. Furthermore, it implies that minimum buffer zones for different landscapes can be determined in a defensible way. This modeling approach can be extended to other bird species with central-place foraging behavior. It provides a helpful tool for landscape planning aimed at minimizing the impacts of wind power on biodiversity.
\end{abstract}

Key Words: collision risk; foraging behavior; impact assessment; individual-based model; Milvus milvus; Red Kite; spatial model; wind power

\section{INTRODUCTION}

The expansion of renewable energy production is encouraged across Europe to mitigate climate change. In many European countries, this entails increasing the number of new onshore wind-power plants. Land scarcity and land-use conflicts make this a challenging task (Ohl and Eichhorn 2010). Determining suitable sites for wind turbines (WTs) requires not only addressing the demands of wind-farm operators, but also considering relevant adverse effects of wind-power generation, e.g., impacts on human health and wildlife.

Biologists have highlighted the potential consequences for bird populations, such as disturbance and displacement (Percival 2000, 2005, Drewitt and Langston 2006, Larsen and Guillemette 2007, Pearce-Higgins et al. 2009). Collisions result in high mortality rates, particularly for raptors observed in the vicinity of WTs (Erickson et al. 2001, Hunt 2002, Barrios and Rodriguez 2004, Smallwood and Thelander 2007, Lekuona and Ursúa 2007, de Lucas et al. 2008, Krijgsveld et al. 2009).

The present study concentrates on the risk of the Red Kite (Milvus milvus) colliding with WTs. This predatory bird belongs to the species with the highest frequencies of rotorblade strikes (Mammen and Dürr 2006, Brandenburg State Bird Conservation Centre (BSBCC) 2010). The reasons for these exceptionally high collision rates are not fully understood, but some facts are important. Wind turbines are often located in open agricultural landscapes, which represent the primary habitat of the Red Kite. Moreover, the ranging (flight) behavior of the raptor within these landscapes fosters collision fatalities. In addition, Red Kites are attracted to areas closer to the turbine, which usually have high abundance of prey (Dürr 2009, Jedicke 2010).

To reduce the impact of WTs on raptors such as the Red Kite, WT sites have to be chosen carefully. In Germany, which hosts about half of the world's Red Kite population, an uncontrolled growth of wind-farm sites occurred in the 1990s. Since then, the federal states have tended to direct the allocation of WTs through regional planning. As a result, WTs are concentrated (and will also in future be concentrated) in certain areas and excluded from others. However, as Madders and Whitfield (2006) point out, planning decisions tend to be based exclusively on subjective judgments, due to the paucity of information on the processes that determine collision risk.

Different scientific approaches have been established for this assessment. One possible approach is spatial modeling (depicting home ranges and behavior) to identify areas of greatest sensitivity for birds at the landscape scale by predicting the ranging activities of the species of interest (Williams et al. 1996, McGrady et al. 1997, McLeod et al. 2003, Madders and Whitfield 2006). Madders and Whitfield (2006) rated such spatial models as good starting points for impact assessments because they are cost effective and can 
identify critical locations. However, statements about the resulting collision risk are hard to derive because the foraging behavior and flight patterns of the species are not considered. A second approach is the use of collision risk models (CRM), first developed by Tucker (1996) and further developed by Biosis Research (2003) and Podolsky (2003, 2005). These consider explicitly the interaction of WTs and birds. The CRMs are based on mathematical equations that incorporate empirical data according to the number of birds observed in the area of the proposed wind farm and the proportion of flight time within the rotor-swept volume. Furthermore, the WT parameters and the size, flight direction, and flight speed of the targeted birds are considered (Madders and Whitfield, 2006). The so-called "Band Collision Risk Model" (Band et al. 2007) is a CRM widely used in the UK.

The spatial models are able to predict whether a species resides in a certain area but provide no information on collision risk. In contrast, CRMs are able to predict collision risks but are designed for specific wind-farm projects and need a lot of input data based on field surveys (Band et al. 2007).

In this study, aspects of both approaches were incorporated into a spatially explicit simulation model, taking into account the Red Kite's flying and foraging behavior and the spatial structure of the landscape. We investigate how the collision risk in a landscape depends on the distance between the WT and the Red Kite's aerie. Such an impact function (IF) has been proposed in a landscape-planning context by Eichhorn and Drechsler (2010). It describes collision risk in a spatially explicit but aggregated way and, therefore, represents a fast and practical tool for collision risk assessment of candidate WT sites. However, the IF used by Eichhorn and Drechsler (2010) predicts impacts only in a qualitative manner and is based on a number of ad hoc assumptions. Thus, its actual form and dependence on species and landscape characteristics remain unclear.

To gain insights into the large-scale effects of species behavior in specific landscapes, agent- or individual-based models (ABM/IBM) are well suited (Huston, et al. 1988, DeAngelis and Mooij 2005, Grimm and Railsback 2005). We developed an ABM for the quantitative prediction of collision risk as a function of the aerie-WT distance and combined it with specific findings from the Band CRM. In our ABM, the "agent" represents a single raptor individual with a ranging behavior depending on habitat requirements and landscape characteristics. To determine collision probabilities for variable aerie-WT distances, virtual experiments were carried out with the ABM. To validate the ABM, a pattern-oriented approach (Wiegand et al. 2003, Grimm et al. 2005) was followed whereby model fitting exercises are carried out between simulated outputs and field observations.

\section{METHODS}

To simulate the Red Kite's foraging flights in response to landscape structure, the model is based on the current knowledge of the behavior of the Red Kite. Such an agentbased approach generally allows for the assessment of speciesspecific vulnerability to particular temporal and/or spatial landscape attributes (e.g., Verboom et al. 1991, Johst et al. 2001, Wichmann et al. 2004, Rodríguez et al. 2006, Bauer et al. 2008). The attribute of concern for a central-place forager like the Red Kite is the location of a WT in the surrounding vicinity of the aerie. The vulnerability is represented by the collision risk of the raptor with this WT. We apply this modeling approach to predict the impact of a WT on a Red Kite in the region of West Saxony.

\section{Model Description}

The model description follows the ODD (Overview, Design concepts, Details) protocol for describing individual- and agent-based models (ABM/IBM) (Grimm et al. 2006).

\section{Purpose}

The purpose of the ABM is to determine the annual mortality of a central-place forager, here the Red Kite, as a function of the distance between the bird's aerie and the WT. For this, the ABM considers the species' foraging behavior as well as the landscape characteristics. The model incorporates the processes essential to understand the interaction between birds and WTs during foraging.

Based on the modeling results, we derive an impact function that quantifies collision risk as a function of aerie-WT distance, and which is comparable to that of Eichhorn and Drechsler (2010). We then explore to what extent such an aggregated approach can capture the synergistic effects of species-specific foraging behavior and landscape structure on collision risk.

\section{State variables and scales}

The ABM includes three types of entities: grid cells that constitute the landscape, a Red Kite, and a WT (see Table 1). In the present study, we consider a model landscape that has a land-use pattern similar to West Saxony, Germany. We chose this region because it falls within the core area of the Red Kite's worldwide distribution.

The Red Kite agent is designed to behave like a typical raptor during foraging flights. Information about its behavior and response to the landscape was derived from our own field observations, expert interviews (Hötker, personal communication 2008), and the literature (Whitfield and Madders 2006b, Nachtigall 2008). Only paired male raptors were considered because of their greater flight activity during the breeding season. Resting behavior was not considered as it does not contribute to collision risk. 
Table 1. Quantities included in the model and their description. Table rows are grouped according to the entities of the model.

\begin{tabular}{|c|c|}
\hline Quantity & Brief description \\
\hline \multicolumn{2}{|l|}{ Landscape Cells } \\
\hline Coordinates & Determine the position of the cell (cell center) in the model landscape. \\
\hline Size & The size of a cell (length $(l)$; width $(w)$ ) represents a real-world dimension of $100 \mathrm{~m} \times 100 \mathrm{~m}$. \\
\hline Number & 10.201 cells, which corresponds to $102 \mathrm{~km}^{2}$ \\
\hline Habitat quality $(h q)$ & $\begin{array}{l}\text { The cells can take integer values for habitat quality }(h q) \text { between } 0 \text { and } 3 . h q=0 \text { represents } \\
\text { unsuitable foraging habitat, e.g., forest. } h q=3 \text { represents the best foraging conditions, e.g., } \\
\text { grassland with a favorable mowing regime. }\end{array}$ \\
\hline \multicolumn{2}{|l|}{ Red Kite } \\
\hline Coordinates & Determine the position of the Red Kite in the model landscape. \\
\hline Flight distance & Length of a straightforward flight: $100 \mathrm{~m}$ \\
\hline Circling radius & Radius of a soaring circle during foraging flight: $100 \mathrm{~m}$ \\
\hline Flight speed & Average speed of the Red Kite: $15 \mathrm{~km} / \mathrm{h}$ (Bruderer and Boldt 2001) \\
\hline Flight height probability $\left(p_{f h}\right)$ & $\begin{array}{l}\text { Probability that the raptor ranges at a height swathed by a WT rotor; based on empirical flight height } \\
\text { distribution }\end{array}$ \\
\hline Flight through rotor probability $\left(p_{r s a}\right)$ & Probability that the raptor flies through the rotor-swept area and does not pass through. \\
\hline Physical collision probability $\left(p_{B A N D}\right)$ & Probability of a bird being hit by a rotor blade if passing orthogonally to rotor-swept area. \\
\hline Collision avoidance probability $\left(p_{a v}\right)$ & The likelihood of a Red Kite actively avoiding collision with a WT. \\
\hline Probability of circling and flying forward $\left(p_{f}\right)$ & $\begin{array}{l}\text { Controls flight behavior during the search flight (see Fig. } 2 \text { ). The variable } p_{f} \text { indicates the probability } \\
\text { of flying forward. The probability of performing a left respectively a right full circle is }\left(1-p_{f}\right) / 2 \text {. }\end{array}$ \\
\hline Maximum residence time on cell $(T)$ & $\begin{array}{l}\text { Determines how long the agent occupies the same cell, given that all neighboring cells are of lower } \\
\text { habitat quality. }\end{array}$ \\
\hline \multicolumn{2}{|l|}{ Wind turbine } \\
\hline Coordinates & Determine the position of the WT in the model landscape. \\
\hline Hub height $(h h)$ & Height of the rotor center: $78 \mathrm{~m}$ \\
\hline Rotor blade length $(r)$ & Half of the rotor diameter: $1 / 2$ of $82 \mathrm{~m}=41 \mathrm{~m}$ \\
\hline
\end{tabular}

The WT is determined by its spatial location relative to the Red Kite aerie-which is located in the center of the model world-and the cell's land-use type.

Most collisions occur during the breeding season when frequent foraging flights take place to feed the nestlings (Mammen and Dürr 2006, Dürr 2009). The breeding season of the Red Kite lasts 85 days (April-June), which defines the length of a model run. Hence, we assume that collisions occurring during this time describe sufficiently well the annual collision risk. The 24-h day includes not only foraging flights but also resting periods and nocturnal behavior. Based on absence times from the aerie observed by Nachtigall (2008), we calculated an average "activity period" (time during which the bird is active and therefore absent from the aerie) of 10.6 $\mathrm{h} /$ day. Resting periods were estimated by Nachtigall (2008) to be about $50 \%$ of the "activity period," so the bird flies for about $5.3 \mathrm{~h} /$ day, or $450 \mathrm{~h} / 85$ days. One model year thus corresponds to $450 \mathrm{~h}$ of flying. To calculate the elapsed time during each model run, we recorded the distance flown and divided it by the raptor's flight speed (Table 1).

\section{Process overview and scheduling}

The ABM is based on three movement processes (random flight, directed flight, and flight forward) and two event processes (collision event and catch the prey). At the beginning of each model step, the bird samples the habitat conditions of the occupied and the neighboring cells. Three conditions are possible:

- The occupied and all neighboring cells are of the same and not of the worst habitat quality, leading to the random-flight procedure. Here, the agent moves one cell forward and then decides with a certain probability (1$\left.p_{f}\right) / 2$ to fly a right or a left full circle, respectively;

- The neighboring cells differ in habitat quality, leading to the directed-flight procedure. Here, the agent moves forward to one of the cells with the best habitat quality and decides with a probability of $\left(1-p_{f}\right) / 2$ to fly a right or a left full circle, respectively; and

- The occupied cell is of the worst habitat quality, initiating the flight forward procedure, where the agent moves one cell $(100 \mathrm{~m})$ forward.

Within these procedures, the two event processes were executed: the "collision-event" procedure and the "catch-theprey" procedure. The collision-event procedure determines under what conditions collisions occur between the Red Kite and the WT. Different circumstances have to coincide for a collision to occur: the raptor has to occupy a cell where a WT is located, it has to fly at a height at which the rotor blades operate, and it has to move through the part of the cell affected by the rotor blades. 
If the raptor crosses the area spanned by the WT rotor blades and does not actively attempt to avoid the strike, it will be hit by a blade. These circumstances are incorporated into the ABM through the determination of the respective probabilities:

1. The basic condition for a collision to occur is that the raptor reaches an area (cell) where a WT is located.

2. The probability that the Red Kite ranges at a height swathed by a WT rotor $\left(p_{f h}\right)$. Taking a WT with hub height $h h=78 \mathrm{~m}$ and rotor length $r=41 \mathrm{~m}$ and using empirical data from Mammen (2010) we estimate a probability of $p_{f h}=0.34$.

3. The probability $\left(p_{r s a}\right)$ of the raptor passing the area affected by the rotor. To derive a simple estimation, we assume that the raptor flies horizontally to the land surface and orthogonally to the plane swept by the rotor. Given that the raptor flies within the height interval determined by the WT's hub height $(h h)$ plus/minus one rotor blade length $(r)$. This results in a flight window spanned horizontally by the cell width $(\mathrm{w}=100 \mathrm{~m})$ and vertically by the rotor diameter $(2 r)$ resulting in a rectangular area of $2 \mathrm{rw}$. The circular area spanned by the rotor blades equals $\pi r^{2}$. Assuming that the flight height distribution within the flight window is uniform, the probability that the raptor flies through the rotor swept area equals:

$$
p_{r s a}=\frac{\pi * r^{2}}{2 r * w}=0.65
$$

4. The probability of a bird being hit when flying through the rotor (i.e., the physical collision probability $p_{B A N D}$ ) is calculated using stage 2 of the Band Collision Risk Model (Band et al. 2007). "The probability depends on the size of the bird (both length and wingspan), the breadth and pitch of the turbine blades, the rotation speed of the turbine, and of course the flight speed of the bird" (Scottish National Heritage (SNH) 2000). The SNH, a nature conservation agency funded by the Scottish Government, provides a template for calculation (SNH 2010). Uncertainties in the wind speed are considered by using different values for the pitch angle of the rotor blades, resulting in values of $p_{B A N D}$ between 0.144 and 0.205 .

5. The probability that the raptor recognizes the threat and actively avoids collision $\left(p_{a v}\right)$. In most cases, raptors scan their surroundings and do actively avoid collisions with infrastructure. This behavior is summarized by the avoidance probability $p_{a v}$. Estimating the avoidance probability is a challenging task (Chamberlain et al. 2006,
Whitfield and Madders 2006a, Whitfield 2009). Smales and Muir (2005) use three arbitrary avoidance probabilities of $95 \%, 98 \%$, and $99 \%$ for collision risk modeling in Australia. Using data of several predatory birds at 13 wind farms in northern Spain, Whitfield and Madders (2006b) empirically estimated avoidance probabilities between $98 \%$ and $100 \%$ with a probable value of $99 \%$ for the Red Kite. In the present study, we consider four possible levels for $p_{a v}: 98 \%, 98.5 \%, 99 \%$, and $99.5 \%$.

Summing up, if the modeled Red Kite occupies the same cell as a WT, its probability of colliding with the WT is:

$$
p_{c o l}=p_{f h} * p_{r s a} * p_{B A N D} *\left(1-p_{a v}\right)
$$

The catch-the-prey procedure determines the point in time when the Red Kite catches a prey and returns to its aerie before it starts the next foraging flight. This procedure is parameterized using the frequency distribution of absence times from the aerie provided by Nachtigall (2008), taking into account that ca. $50 \%$ of the absence time is used for flying (see subsection State Variables and Scales). This frequency distribution of flight times is discrete by providing the probability of observing a flight time within a particular interval. We assume that within each of these time intervals the flight times are equally distributed to obtain a continuous probability density function of flight times (Fig. 1). A flow chart of the ABM with the described procedures is given in Fig. 2.

Fig. 1. Probability density function of flight duration based on Nachtigall (2008).

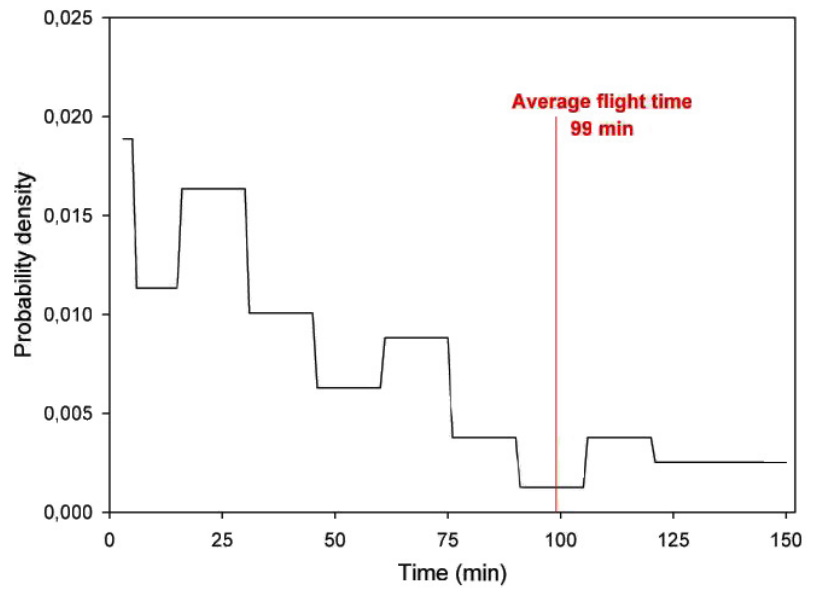


Fig. 2. Process overview.

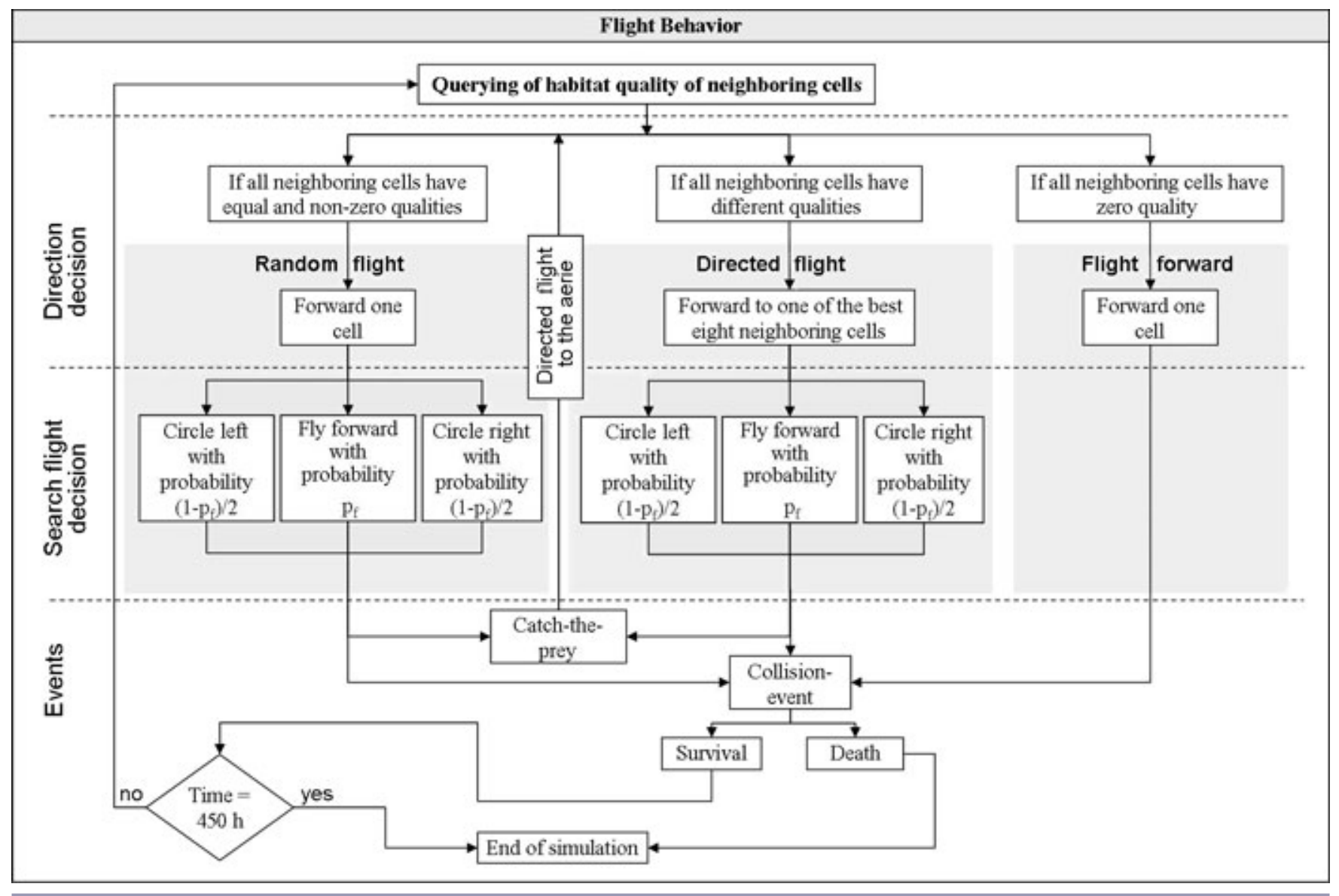

\section{Relevant design concepts}

\section{Stochasticity}

The virtual landscape is generated randomly, assuming fixed shares of the different habitat types. Furthermore, the behavioral decisions of the raptor during its flight are largely stochastic and, among others, depend on the probability $p_{f}$ of flying forward and the probability density function of the flight duration (Fig. 1). The model was run 10,000 times and relevant variables were statistically analyzed.

\section{Initialization}

The model landscape is initialized by creating a random landscape for each simulation run. The number of cells with a particular habitat quality $(h q=0,1,2,3)$ is fixed and based on the landscape structure in the region of West Saxony. The Red Kite agent is initialized at the aerie placed in the center of the model world. The WT entity is initialized at a randomly chosen location limited by two constraints. First, it can only be located on suitable habitat cells so, e.g., forest $(h q=0)$ is excluded. Second, it is located at a specified distance to the aerie, which varies between $100 \mathrm{~m}$ and $500 \mathrm{~m}$ in steps of 200 $\mathrm{m}$ and from 500 to $5,000 \mathrm{~m}$ in steps of $500 \mathrm{~m}$.

Input

Input data are used for two procedures. First, the proportions of land-use types, observed in our reference region West Saxony, are used to generate a virtual landscape. The region is characterized by a high proportion of open agricultural land and a small proportion of forested area. The different land-use types extracted from real land-cover data (ATKIS 2007) are summarized into four classes with different habitat quality levels. Grassland and pasture have the highest habitat quality $(h q=3)$ and comprise about $11 \%$ of West Saxony, habitat quality $h q=2$ (e.g., croplands) comprises about 55\%, and habitat quality $h q=1$ (e.g., settlements) comprises about $4 \%$ whereas forested area is of the lowest quality $(h q=0)$ and comprises about $17 \%$ of the landscape.

\section{Interaction}

The Red Kite agent interacts with the surrounding landscape whereby the quality of the landscape influences the flight 
behavior of the agent. A second interaction takes place between the Red Kite and the WT. If the conditions defined in the collision-event process (see section Process Overview and Scheduling) are fulfilled, the Red Kite collides with the WT.

\section{Validation of Simulated Foraging Behavior}

We validated the foraging behavior in the model by comparing its output to empirical behavior data. Although detailed field data for the Red Kite were rare, residence frequencies outside the aerie in a certain distance class to the aerie and its maximum distance to the aerie were determined by Nachtigall (2008) and have been used for validation.

\section{Strategies}

There are two model parameters, which predominantly control the flight behavior of the Red Kite agent: the probability $p_{f}$ of flying forward and the maximum residence time $T$ on a cell during the flights. Due to their uncertainties, plausible values are estimated by pattern-oriented modeling (Grimm et al. 2005). The probability $p_{f}$ ranges from 0 to 1 and the residence time $T$ ranges from $1.2 \mathrm{~min}$ to $12 \mathrm{~min}$ (Nachtigall, personal communication, 2009). Varying $p_{f}$ in steps of 0.1 and $T$ in steps of $1.2 \mathrm{~min}$, and systematically combining $p_{f}$ and $T$ for all values leads to 110 parameter combinations, henceforth termed "strategies."

\section{Determination of best strategies}

To determine which of these strategies leads to the best fit between modeled and empirical behavior, we ran the model 10,000 times for each strategy and recorded the residence frequencies $x_{i}$ of the raptor in four different distance classes $(i$ $=1, \ldots, 4)$ from the aerie: between 0 and $1 \mathrm{~km}(i=1)$, between 1 and $2 \mathrm{~km}(i=2)$, between 2 and $3 \mathrm{~km}(i=3)$, and greater than $3 \mathrm{~km}(i=4)$. Nachtigall (2008) determines frequencies for these distance classes of: $y_{1}=0.6, y_{2}=0.2, y_{3}=0.15$, and $y_{4}=0.05$ for male Red Kites. Besides the distance classes, we compared the modeled maximum distance from the aerie (denoted as $k$ ) with the value $1_{\max }=4,500 \mathrm{~m}$ observed in the field by Nachtigall (2008).

The relative deviation $\sigma_{i}$ of $x_{i}$ from the empirical data $y_{i}$ for each distance class (i) was calculated by

$$
\sigma_{i}=\frac{\left|x_{i}-y_{i}\right|}{y_{i}} \text { for } \mathrm{i}=1,2, \ldots 4
$$

and the mean relative deviation over all distance classes $\sigma_{\text {distclas }}$ by

$$
\sigma_{\text {distclass }}=\frac{1}{4} \sum_{i=1}^{4} \sigma_{i}
$$

The relative deviation $\sigma_{\text {maxdist }}$ with regard to the maximum distance was calculated by

$$
\sigma_{\max d i s t}=\frac{\left|k-l_{\max }\right|}{l_{\max }}
$$

By minimizing $\sigma_{\text {distclass }}$ and $\sigma_{\text {maxdist }}$, we identified the strategies that best fit the empirical data.

\section{Collision Risk Analysis}

For the strategies that provide the best model fit to the empirical data, we determined the collision risk for a set of scenarios. Each scenario is defined by a combination of aerieWT distances and the avoidance probability $p_{a v}$. The aerieWT distance ranges in 11 steps from 100 to $5,000 \mathrm{~m}$ and the avoidance probability $p_{a v}$ in three steps from 0.98 to 0.995 (see subsection Process Overview and Scheduling), leading to a total of 48 scenarios.

We ran the model 10,000 times for the best strategies and the 48 scenarios. For every model run, a random landscape with the same proportions of habitat types as in the study region was generated, the WT was placed randomly at the specified distance from the aerie, and we recorded whether a collision occurred or not. The collision risk was then calculated for each scenario by dividing the number of collision events by the number of model runs.

\section{RESULTS}

\section{Foraging Behavior}

The flight behavior in the model is characterized by flying forward probability and residence time on a cell. For 110 different strategies, each defined by a combination of the probability of flying forward $p_{f}$ and the maximum residence time $T$, the relative deviations between modeled and empirical data (Nachtigall 2008) for $\sigma_{\text {distclass }}$ and $\sigma_{\text {maxdist }}$ were calculated as detailed in the Methods sub-section "Validation of foraging behavior," above.

Figure 3 shows the results of the model fit for frequencies the raptor is observed in different distance classes as a function of $p_{f}$ and $T$. It strongly varies for $p_{f}$ but depends only weakly on $T$. The minimum relative deviation $\sigma_{\text {distclass }}$ of 0.17 is found for strategy $p_{f}=0.4, T=12 \mathrm{~min}$.

A model fit was also applied for maximum flight distance to the aerie $\left(\sigma_{\text {maxdiss }}\right)$ as a function of $p_{f}$ and $T$. Similar to $\sigma_{\text {distclass }}$ in Fig. $3, \sigma_{\text {maxdist }}$ strongly varies for $p_{f}$ but depends only weakly on $T$. The minimum relative deviation $\sigma_{\text {maxdist }}$ of 0.01 is obtained for strategy $p_{f}=0.3$ and $T=3.6 \mathrm{~min}$. 
Fig. 3. Relative deviation $\sigma \_$distclass between model output and empirical data as a function of the model parameters $\mathrm{pf}$ and $\mathrm{T}$ (for details see text).

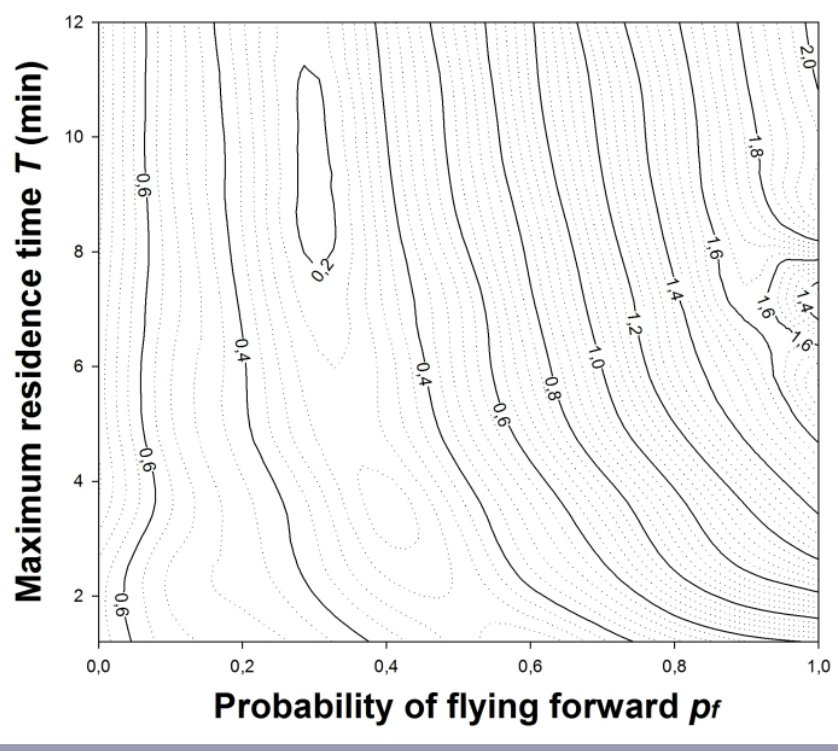

The two strategies derived from the model fits $\left(p_{f}=0.4, T=\right.$ $12 \mathrm{~min}$ and $p_{f}=0.3, T=3.6 \mathrm{~min}$ ) represent similar levels for $p_{f}(0.4$ vs. 0.3$)$ and differ considerably in $T(12 \mathrm{~min}$ vs. 3.6 min). However, as noted above, the level of $T$ only weakly determines the deviation between model output and the observed values (Nachtigall 2008). Therefore, both strategies provide a satisfactory model fit with relative deviations below $20 \%$. As strategy $p_{f}=0.4, T=12 \mathrm{~min}$ performs slightly better with regard to $\sigma_{\text {distclass }}$ whereas strategy $\left(p_{f}=0.3\right.$ and $T=3.6$ min) performs better for $\sigma_{\text {maxdist }}$, we consider both in the analysis of the collision risk.

\section{Collision risk}

Our model fit concerning the flight behavior revealed two strategies that correspond to observed field data. For these strategies, $\left(p_{f}=0.4, T=12 \mathrm{~min}\right.$, Fig. $4 \mathrm{~b}, \mathrm{~d}$, and $p_{f}=0.3$ and $T=3.6 \mathrm{~min}$, Fig. 4a,c), the collision risk analysis was performed and the impact function was derived.

Figure 4 shows collision risk in terms of the annual mortality rate as a function of aerie-WT distances for four avoidance probabilities $p_{a v}$ and two different physical collision probabilities $p_{B A N D}$. As expected, the collision risk decreases with increasing aerie-WT distance. The curves have an exponential shape so that the collision risk declines rapidly near the aerie and more slowly at greater distances. These impact functions show that an exponential dependency (i.e., $\exp$ (-distance)) is more appropriate than the bell-shaped impact function (i.e., $\exp \left(-\right.$ distance $\left.^{2}\right)$ ) assumed in our previous study (Eichhorn and Drechsler 2010).
The impact function generally depends on the residence time $T$, the avoidance probability $p_{a v}$, and the physical collision probability $p_{B A N D}$. A flight behavior with shorter residence time results in a higher annual mortality rate due to WT collision. Decreasing the avoidance probability increases the collision risk. For example, at short aerie-WT distances $(<1500 \mathrm{~m})$ it varies up to 0.4 in mortality rate for $p_{a v}$ between 0.98 and 0.995 . An increase in $p_{B A N D}$ due to increasing wind speeds displays a higher probability for the raptor to be hit by the rotor blade, due to geometrical changes in the WT rotor blades in adaption to higher wind speeds (Fig. 4a,b vs. Fig. 4c,d).

\section{DISCUSSION}

An important step toward improving the sustainability of wind energy expansion is the assessment of the ecological impact of WTs in terms of the collision risk they pose for bird species. An aspect that has been rarely investigated for this assessment is the relationship between collision risk and the distance between a bird's aerie and a WT in the landscape. Therefore, we developed an agent-based model with which we investigated this relationship for a foraging predatory bird species. Among the species that are endangered and suspected to be impacted by WTs is the Red Kite. The agent-based model simulates foraging flight patterns of the Red Kite and predicts annual mortality rates due to collisions with a WT at different distances from the aerie.

From these simulations, we were able to derive a so-called impact function that describes the functional relationship between the annual collision risk and the aerie-WT distance. It aggregates the interplay of the species-specific foraging behavior and the landscape structure including the presence of a WT. We found that the collision risk declines exponentially with increasing distance between a bird's aerie and the WT. The strength of this decline sensitively depended on the implemented avoidance probability $p_{a v}$ that specifies the likelihood of a bird actively avoiding being hit by a rotor blade and the bird's specific flight behavior (given by the parameters $T$ and $p_{f}$, see Table 1).

Therefore, we calculated the impact function for four different avoidance probabilities that cover the values given by Whitfield and Madders (2006b) and demonstrated the range of uncertainty in collision risk. The simulated flight behavior of the Red Kite was validated by comparing model output to field data on the frequency of a bird observed in particular distance classes and its maximum flight distance to its aerie. The relative deviation between modeled and observed frequencies was found to be below $20 \%$. It should be noted that, in the present model, the flight behavior of the Red Kite depends on the actual environmental conditions, including a random component, but not on memory. In reality, certain sectors around the aerie are more preferred than others because raptors are expected to be able to remember good hunting areas (Nachtigall, personal communication, 2009). However, 
Fig. 4. Annual collision risk (mortality rate) as a function of the distance between aerie and WT for different collision avoidance probabilities. Panel (a) is obtained for strategy ( $\mathrm{pf}=0.3$ and $\mathrm{T}=3.6 \mathrm{~min}$ )_with pBAND $=0.144$, panel $(\mathrm{b})$ for strategy $(\mathrm{pf}=0.4, \mathrm{~T}=12 \mathrm{~min})$ with $\mathrm{pBAND}=0.144$, panel $(\mathrm{c})$ for strategy $(\mathrm{pf}=0.3$ and $\mathrm{T}=3.6 \mathrm{~min})$ with $\mathrm{pBAND}=0.205$, and panel $(\mathrm{d})$ for strategy $(\mathrm{pf}=0.4, \mathrm{~T}=12 \mathrm{~min}$ ) with $\mathrm{pBAND}=0.205$.

(a)

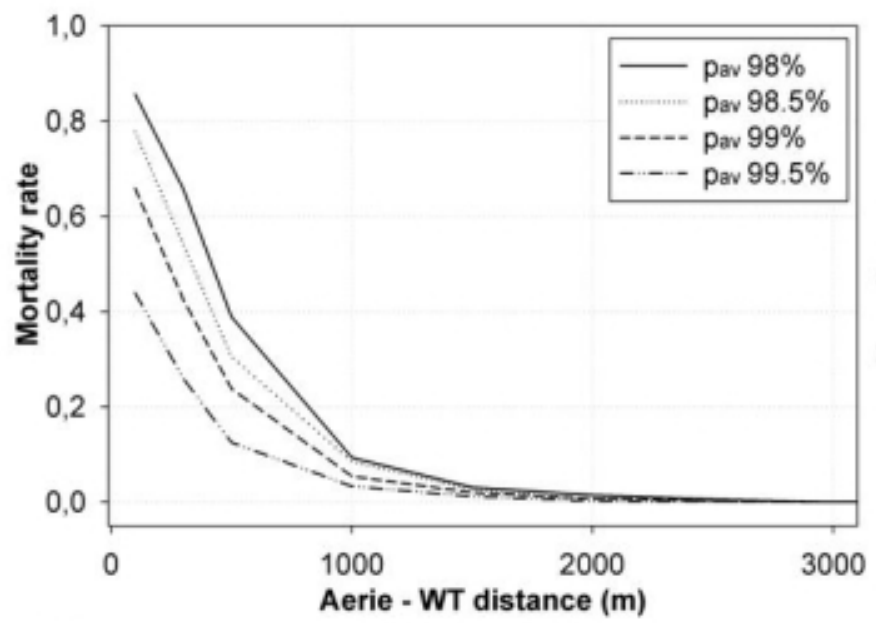

(c)

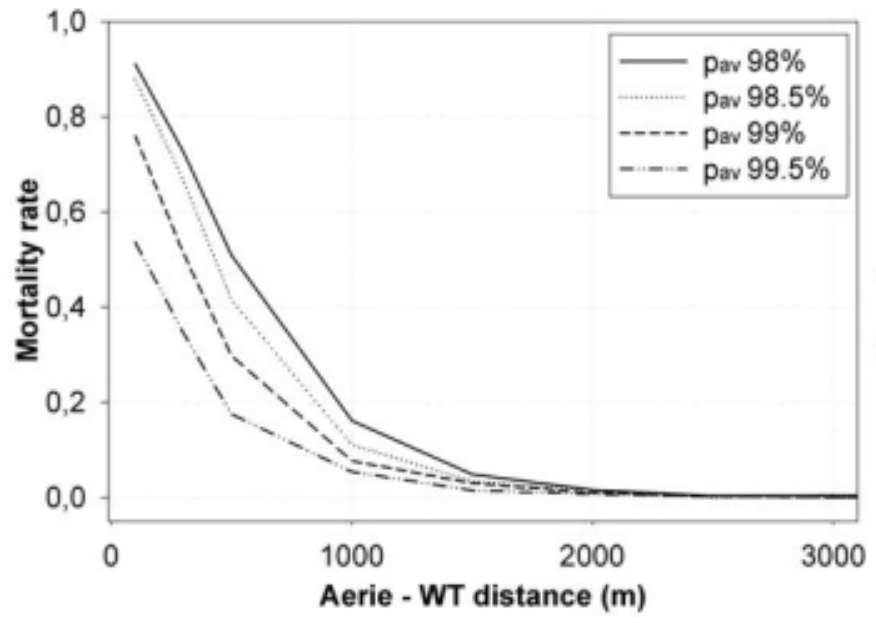

(b)

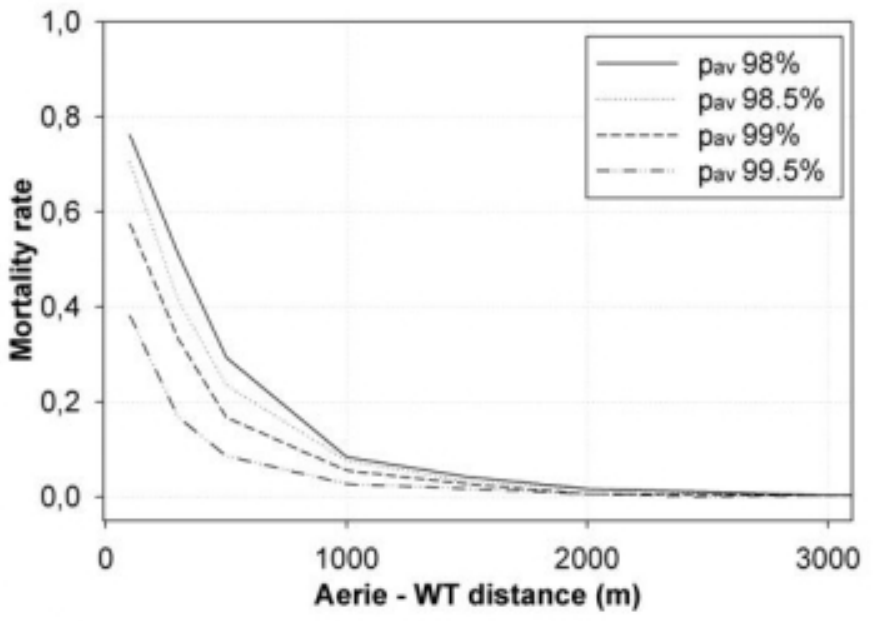

(d)

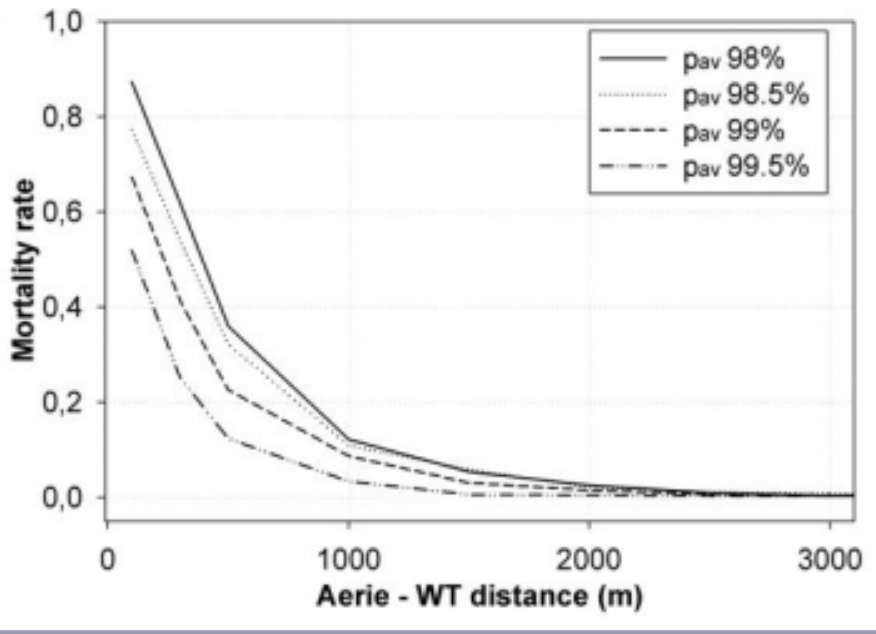

adequate empirical data are missing. A possible experimental approach to gain better knowledge about foraging behavior of birds is, e.g., GPS satellite telemetry, which has been successfully applied for the telemetry of migratory flights (Meyburg and Pfeiffer 2009). Similar data, if available for the ranging behavior during the breeding season, could be incorporated into the agent-based model as our approach is flexible enough to allow for the incorporation of improved movement rules.

As comparable field data are missing, we validated the derived impact function indirectly using two major field studies (Hötker et al. 2006, Dürr 2009). These studies did not consider the dependency of mortality rates on aerie-WT distances but monitored the number of dead birds per turbine per year in different regions. Hötker et al. (2006) estimated that around 100 Red Kites are killed by WTs in Germany per year. Assuming an equal distribution of bird strikes in Germany and taking into account the total number of WTs $(16,500 \mathrm{WT}$; Bundesverband Windenergie (BWE) 2010), this results in an annual collision risk per turbine of 0.006 . The second study (Dürr 2009) used records from the German Federal State of Brandenburg, a region neighboring West Saxony. The number of collisions of Red Kites with WTs was recorded between 2001 and 2009. From these data, Dürr (2009) estimated an annual rate of collision per turbine of 0.028 . In the derived 
impact function, the collision rates of these two studies correspond to aerie-WT distances of 2,000-2,500 m and $1,300-1,500 \mathrm{~m}$, respectively. These two ranges of derived distances correspond well to observed aerie-WT distances in the region and also fit typical flight distances of the Red Kite (Nachtigall 2008). The derived impact function is, therefore, indirectly validated.

If there are several WTs at different distances in the landscape, the probability of not colliding with any of these is the product of the probabilities of not colliding with each individual WT. The individual collision probabilities can be obtained from the derived impact function. Alternatively, the model could be run simultaneously with several WTs in the model landscape. Hence, the model can also be used to assess the effect of wind farms.

The investigation of the consequences of collision risk on population dynamics is interesting because it is unclear whether the additional mortalities caused by the WTs lead to a population decline or whether they only compensate for density-dependent population regulation. Using the VORTEX Population Viability Analysis Software package (see http://w ww.vortex9.org/vortex.html), Hötker et al. (2006) demonstrated a clear tendency toward a population decline caused by the inclusion of WT-induced mortality. The study concluded that there is a need for better data sets on mortality due to collision with WTs. Our calculated mortality rates and the resulting impact function can be used as inputs to such population viability analyses and can, therefore, directly contribute to a better estimation of population trends. Moreover, the impact function can be used to assess the size of buffer zones around aeries in which the erection of WTs is forbidden to minimize the negative impact of wind power development on birds.

Our modeling approach could be applied to other raptor species as well, provided that the foraging behavior and the parameters are adapted appropriately. Adaption to other regions is also possible. In both cases, sufficient field data are required to parameterize the model. In particular, it would be interesting to compare the impact functions obtained for different species and different landscapes, thus supporting a comprehensive assessment of the ecological consequences of wind power development.

\section{CONCLUSION}

The analysis of our agent-based modeling approach reveals that the synergistic effects of foraging behavior and landscape structure can be captured by an aggregated relationship of collision risk as a function of the aerie-WT distance. Therefore, our approach of deriving impact functions through agent-based modeling provides a helpful tool in landscape planning for wind power development and helps meet renewable energy targets in a sustainable manner.

The derived impact function, combined with an ecologicaleconomic analysis proposed by Eichhorn and Drechsler
(2010), allows determination of so-called trade-offs between wind energy production and Red Kite protection. These tradeoffs show the functional relationship between increasing wind energy production and the resulting ecological impact.

The quantitative specification of the impact function for a certain species in a certain landscape, including its validation by field data, is important for using it in concrete planning and design processes of wind power developments. Therefore, for endangered species, sufficient field data to parameterize and validate such agent-based models are essential.

Responses to this article can be read online at: http://www.ecologyandsociety.org/vol17/iss2/artl/responses/

\section{Acknowledgments:}

We would like to thank Winfried Nachtigall and Herman Hötker for empirical support and advice on ornithological questions during the model development. We would also like to thank Jan Engel and Andreas Thiele for inspiring discussions, technical support, and programming hints. The authors wish to thank the Ministry for Education and Research for funding the research project "Conflicts of interest over wind power" [Nachhaltige Landnutzung im Spannungsfeld umweltpolitisch konfligierender Zielsetzungen am Beispiel der Windenergiegewinnung] (Grant No. 01UN0601A, B) as part of the Fona Program "Economics for Sustainability [Wirtschaftswissenschaften für Nachhaltigkeit] (WIN)". This work was further supported by the Helmholtz Impulse and Networking Fund through the Helmholtz Interdisciplinary Graduate School for Environmental Research (HIGRADE).

\section{LITERATURE CITED}

ATKIS. 2007. The Authoritative Topographic-Cartographic Information System ATKIS®-DGM25. License number: 3219/07, Ordnance Survey Saxony, Dresden, Germany.

Band, W., M. Madders, and D. P. Whitfield. 2007. Developing field and analytical methods to assess avian collision risk at wind farms. Pages 259-275 in M. de Lucas, G. F. E. Janss, and M. Ferrer, editors. Birds and wind farms: risk assessment and mitigation. Quercus, Madrid, Spain.

Barrios, L., and A. Rodriguez. 2004. Behavioural and environmental correlates of soaring-bird mortality at on-shore wind turbines. Journal of Applied Ecology 41:72-81. http://d x.doi.org/10.1111/j.1365-2664.2004.00876.x

Bauer, S., M. van Dinther, K.-A. Høgda, M. Klaassen, and J. Madsen. 2008. The consequences of climate-driven stop-over sites changes on migration schedules and fitness of Arctic geese. Journal of Applied Ecology 77:654-660. http://dx.doi. org/10.1111/j.1365-2656.2008.01381.x 
Biosis Research. 2003. Avian modelling addendum to Timewell and Meredith 2002. Appendix 6a. Report for the Hydro-Electric Company. Biosis Research, Melbourne, Australia.

Brandenburg State Bird Conservation Centre (BSBCC). 2010. Vogelverluste an Windenergieanlagen in Deutschland. Zentrale Fundkartei. Staatliche Vogelschutzwarte im Landesamt für Umweltamt, Gesundheit und Verbraucherschutz Brandenburg zusammengestellt: Tobias Dürr. BSBCC, Brandenburg, Germany. [online] URL:

http://www.mugv.brandenburg.de/cms/media.php/lbm1.a.2334. de/wka vogel.xls.

Bruderer, B., and A. Boldt. 2001. Flight characteristics of birds: I. radar measurements of speeds. Ibis 143:178-204.

http://dx.doi.org/10.1111/j.1474-919X.2001.tb04475.x

Bundesverband Windenergie e.V. (BWE). 2010. Die Entwicklung der Windenergie in Deutschland 2009. [online] URL:

http://www.wind-energie.de/de/statistiken/charts/365/0/statistik. csv.

Chamberlain, D. E., M. R. Rehfisch, A. D. Fox, M. Desholm, and S. Anthony. 2006. The effect of avoidance rates on bird mortality predictions made by wind turbine collision risk models. Ibis 148:198-202. http://dx.doi.org/10.1111/j.1474-9 19X.2006.00507.X

DeAngelis, D. L., and W. M. Mooij. 2005. Individual-based modelling of ecological and evolutionary processes. Annual Review of Ecology, Evolution and Systematics 36:147-168. http://dx.doi.org/10.1146/annurev.ecolsys.36.102003.152644

de Lucas, M., G. F. E. Janss, D. P. Whitfield, and M. Ferrer. 2008. Collision fatality of raptors in wind farms does not depend on raptor abundance. Journal of Applied Ecology 45:1695-1703. http://dx.doi.org/10.1111/j.1365-2664.2008.01549. $\underline{x}$

Drewitt, A. L., and R. H. W. Langston. 2006. Assessing the impacts of wind farms on birds. Ibis 148:29-42. http://dx.doi. org/10.1111/j.1474-919X.2006.00516.X

Dürr, T. 2009. Zur Gefährdung des Rotmilans Milvus milvus durch Windenergieanlagen in Deutschland. Informationsdienst Naturschutz Niedersachsen 29:185-191.

Eichhorn, M., and M. Drechsler. 2010. Spatial trade-offs between wind power production and bird collision avoidance in agricultural landscapes. Ecology and Society 15: 10. [online] URL: http://www.ecologyandsociety.org/vol15/iss2/ $\underline{\operatorname{art} 10 /}$.

Erickson, W. P., G. D. Johnson, M. D. Strickland, D. P. Young, K. J. Sernka, and R. E. Good. 2001. Avian collisions with wind turbines: a summary of existing studies and comparisons of avian collision mortality in the United States. NWCC and RESOLVE Inc., King City, Ontario, Canada and LGL Ltd. and RESOLVE Inc., Washington, D.C., USA.

Grimm, V., U. Berger, F. Bastiansen, S. Eliassen, V. Ginot, J. Giske, J. Goss-Custarrd, T. Grand, S. Heinz, G. Huse, A. Huth, J. U. Jepsen, C. Jørgensen, W. M. Mooij, B. Müller, G. Pe'er, C. Piou, S. F. Railsback, A. M. Robbins, M. M. Robbins, E. Rossmanith, N. Rüger, E. Strand, S. Souissi, R. A. Stillman, R. Vabø, U. Visser, and D. L. DeAngelis. 2006. A standard protocol for describing individual-based and agent-based models. Ecological Modelling 198:115-126. http://dx.doi.org /10.1016/j.ecolmodel.2006.04.023

Grimm, V., and S. F. Railsback. 2005. Individual-based modelling and ecology. princeton series in theoretical and computational biology. Princeton University Press, Princeton, New Jersey, USA and Oxford, UK. http://dx.doi.org/10.1016/ $\underline{\text { S0304-3800(98)00186-0 }}$

Grimm, V., E. Revilla, U. Berger, F. Jeltsch, W. M. Mooij, S. F. Railsback, H. H. Thulke, J. Weiner, T. Wiegand, and D. L. DeAngelis. 2005. Pattern-oriented modelling of agent-based complex systems: lessons from ecology. Science 310:987991. http://dx.doi.org/10.1126/science.1116681

Hötker, H., K.-M. Thomsen, and H. Jeromin. 2006. Impacts on biodiversity of exploitation of renewable energy sources: the example of birds and bats-facts, gaps in knowledge, demands for further research, and ornithological guidelines for the development of renewable energy exploitation. Michael-Otto-Institut im NABU, Bergenhusen, Germany.

Hunt, G. 2002. Golden Eagles in a perilous landscape: predicting the effects of mitigation for wind turbine bladestrike mortality. Consultant Report 500-02-043F, PIER Environmental Area. Prepared for: California Energy Commision, Sacramento, California, USA.

Huston, M., D. DeAngelis, and W. Post. 1988. New computer models unify ecological theory. BioScience 38:682-691. http ://dx.doi.org/10.2307/1310870

Jedicke, E. 2010. Rotmilan und Windkraft. Naturschutz und Landschaftsplanung 43:35.

Johst, K., R. Brandl, and R. Pfeifer. 2001. Foraging in a patchy and dynamic landscape: human land use and the white stork. Ecological Applications 11:60-69. http://dx.doi.org/10.1890/ 1051-0761(2001)011[0060:FIAPAD]2.0.CO;2

Krijgsveld, K. L., K. Akershoek, F. Schenk, F. Dijkf, and S. Dirksen. 2009. Collision risk of birds with modern large wind turbines. Ardea - Official journal of the Netherlands Ornithologists' Union 97:357-366. http://dx.doi.org/10.5253 /078.097.0311

Larsen, J. K., and M. Guillemette. 2007. Effects of wind turbines on flight behavior of wintering common eiders: 
implications for habitat use and collision risk. Journal of Applied Ecology 44:516-522. http://dx.doi.org/10.1111/j.136 5-2664.2007.01303.x

Lekuona, J. M., and C. Ursúa. 2007. Avian mortality in wind power plants of Navara (northern Spain). Pages 177-192 in M. de Lucas, G. Janss, and M. Ferrer. 2007. Birds and wind farms: risk assessment and mitigation. Quercus/ Liberia Linneo, Madrid, Spain.

Madders, M., and D. P. Whitfield. 2006. Upland raptors and the assessment of wind farm impacts. Ibis 148:43-56. http://d X.doi.org/10.1111/j.1474-919X.2006.00506.x

Mammen, U. 2010. Aktueller Wissensstand zum Konfliktfeld "Rotmilan und Windkraft". [online] URL: http://www.windenergie.de/fileadmin/dokumente/Themen_A-Z/

Vogelschutz/07_Mammen_Rotmilan.pdf.

Mammen, U., and T. Dürr. 2006. Rotmilane und Windkraftanlagen - Konflikt oder übertreibung? APUS Beiträge zur Avifauna Sachsen-Anhalts 13:73-74.

McGrady, M. J., D. R. A. McLeod, S. J. Petty, J. R. Grant, and I. P. Bainbridge. 1997. Golden eagles and forestry. Forestry Commission Research Information Note 292. Forestry Commission, Roslin, UK.

McLeod, D. R. A., D. P. Whitfield, A. H. Fielding, P. F. Haworth, and M. J. McGrady. 2003. Predicting home range use by golden eagles Aquila chrysaetos in western Scotland. Avian Science 2:183-198.

Meyburg, B. U., and T. Pfeiffer. 2009. GPS-SatellitenTelemetrie als neue Methode in der Forschung am Rotmilan Milvus milvus. Informationsdienst Naturschutz Niedersachsen 29:211.

Nachtigall, W. 2008. Der Rotmilan (Milvus milvus, L 1758) in Sachsen und Südbrandenburg - Untersuchungen zur Verbreitung und ökologie. Dissertation, Martin-LutherUniversität Halle - Wittenberg. [online]

URL: http://sundoc.bibliothek.uni-halle.de/diss-online/08/08H218/ prom.pdf.

Ohl, C., and M. Eichhorn. 2010. The mismatch between regional spatial planning for wind power development in Germany and national eligibility criteria for feed-in tariffsa case study in West Saxony. Land Use Policy 27:243-254. http://dx.doi.org/10.1016/j.landusepol.2009.06.004

Pearce-Higgins, J. W., L. Stephen, R. H. W. Langston, I. P. Bainbridge, and R. Bullman. 2009. The distribution of breeding birds around upland wind farms. Journal of Applied Ecology 46:1323-1331.

Percival, S. M. 2000. Birds and wind turbines in Britain. British Wildlife 12:8-15.

Percival, S. M. 2005. Birds and wind farms: what are the real issues? British Birds 98:194-204.
Podolsky, R. 2003. Avian risk of collision (ARC) model. NWCC Biological Significance Workshop, 17-18 November 2003. National Wind Coordinating Committee, Washington, D.C., USA.

Podolsky, R. 2005. Application of risk assessment tools: avian risk of collision model. Pages 86-87 in S. S. Schwartz, editor. Proceedings of the Onshore Wildlife Interactions with Wind Developments, Research Meeting V, Lansdowne, Virginia, 34 November 2004. Prepared for the Wildlife Subcommittee of the National Wind Coordinating Committee. RESOLVE, Incorporated, Washington, D.C., USA.

Rodríguez, C., K. Johst, and J. Bustamante. 2006. How do crop types influence breeding success in lesser kestrels through prey quality and availability? A modeling approach. Journal of Applied Ecology 43:587-597. http://dx.doi.org/10 .1111/j.1365-2664.2006.01152.x

Scottish National Heritage (SNH). 2000. Wind farms and birds: calculating a theoretical collision risk assuming no avoiding action. Guidance Note Series, Scottish Natural Heritage. [online] URL: http://www.snh.gov.uk/docs/C205425. pdf.

Scottish National Heritage (SNH). 2010. Assessing collision risk - a calculation template in Excel. [online] URL: http:// www.snh.gov.uk/docs/C234672.xls.

Smales, I., and S. Muir. 2005. Modelled cumulative impacts on the Tasmanian wedge-tailed eagle of wind farms across the species' range. Project no. 4857. Report for the Department of Environment and Heritage. Biosis Research Pty. Ltd.

Smallwood, K. S., and C. Thelander. 2007. Bird mortality in the Altamont pass wind resource area, California. Journal of Wildlife Management 72:215-223. http://dx.doi.org/10.2193/ 2007-032

Tucker, V. A. 1996. A mathematical model of bird collisions with wind turbine rotors. Journal of Solar Energy Engineering 118:253-262. http://dx.doi.org/10.1115/1.2871788

Verboom, J., A. Schotman, P. Opdam, and J. A. J. Metz. 1991. European Nuthatch metapopulations in fragmented agriculture landscapes. Oikos 61:149-156. http://dx.doi.org/1 $\underline{0.2307 / 3545332}$

Whitfield D. P. 2009. Collision avoidance of golden eagle at wind farms under the 'Band' Collision Risk Model. Natural Research Ltd., Banchory, UK.

Whitfield D. P., and M. Madders. 2006a. A review of the impacts of wind farms on hen harriers Circus cyaneus and estimation of collision avoidance rates. Natural Research Information Note 1, Natural Research Ltd., Banchory, UK.

Whitfield, D. P. and M. Madders. 2006b. Deriving collision avoidance rates for Red Kites Milvus milvus. Natural Research Information Note. Natural Research Ltd., Banchory, UK. 
Wichmann, M. C., W. R. J. Dean, and F. Jeltsch. 2004. Global change challenges the Tawny eagle (Aquila rapax): modelling extinction risk with respect to predicted climate and land use changes. Ostrich 75:204-210. http://dx.doi.org/10.2989/0030 $\underline{6520409485446}$

Wiegand, T., F. Jeltsch, I. Hanski, and V. Grimm. 2003. Using pattern-oriented modelling for revealing hidden information: a key for reconciling ecological theory and application. Oikos 100:209-222. http://dx.doi.org/10.1034/j.1600-0706.2003.12027. $\underline{\mathrm{x}}$

Williams, P. H., D. Gibbons, C. Margules, A. Rebelo, C. Humphries and R. Pressey. 1996. A comparison of richness hotspots, rarity hotspots and complementary areas for conserving diversity using British birds. Conservation Biology 10:15-74. http://dx.doi.org/10.1046/j.1523-1739.1996.10010155. 